\title{
Obesity: A Risk Factor for Acute Myocardial Infarction with Angiographically Patent Epicardial Coronary Vessels in an Adolescent
}

\author{
Ayman A. El-Menyar Mohammed M. Gomaa Salah E.O. Arafa \\ Department of Cardiology, Hamad General Hospital, Hamad Medical Corporation, Doha, Qatar
}

\section{Key Words}

Obesity · Coronary spasm • Myocardial infarction, adolescent

\begin{abstract}
Objective: To report a causal relationship between myocardial infarction (MI) and obesity in an adolescent in the absence of the well-known risk factors for MI. Case Presentation and Intervention: A morbidly obese 17-year-old male, a nonsmoker, nondiabetic and normotensive patient, who sustained acute inferior MI with no family history of coronary artery disease, presented with central chest pain. ECG showed low voltage, normal sinus rhythm and ST segment elevation in the inferior leads; cardiac enzymes were elevated. Screening for ethanol and cocaine were negative. He was admitted to the coronary-care unit as a case of inferior MI with late presentation. Cardiac catheterization revealed patent epicardial coronary arteries; short- and long-term plans for weight reduction and family counseling were started. The hospital stay was uneventful, and the patient was discharged home on the fourth day. Conclusion: Based on clinical and laboratory findings, we assume that the MI might partly be secondary to coronary artery spasm or invisible premature atherosclerotic plaques. Public education and awareness for this complication in a young obese patient are warranted.

Copyright $\odot 2006$ S. Karger AG, Basel
\end{abstract}

\section{Introduction}

Obesity among youthful populations is a common problem in the Gulf area [1-4]. Patients with acute myocardial infarction (AMI) and normal epicardial coronary arteries tend to be young and have relatively few coronary risk factors; however, they often have a history of cigarette smoking and a positive family history for coronary artery disease greater than older patients. The clinical, laboratory and electrocardiographic features of AMI are otherwise indistinguishable from those present in the overwhelming majority of patients with AMI who have atherosclerotic coronary heart disease [5]. Recent data from surveillance studies of myocardial infarction (MI) suggest that excess weight is the most common cardiovascular risk factor in patients with MI and that its prevalence has increased over time [6]. The underlying mechanism of MI in obese patients in the absence of other risk factors is not clear.

\section{Case Report}

A 17-year-old Syrian male patient living in Qatar since birth, who is a nonsmoker, nondiabetic and normotensive with no family history of coronary artery disease and no acknowledged drug abuse, presented to the emergency department with central chest pain during the previous night. The pain was crushing in nature,

\section{KARGER}

Fax +4161306 1234

E-Mail karger@karger.ch

www.karger.com (c) 2006 S. Karger AG, Basel

$1011-7571 / 06 / 0156-0449 \$ 23.50 / 0$

Accessible online at:

www.karger.com/mpp
Ayman Ahmed El-Menyar, MD, MRCP (UK)

Department of Cardiology and Cardiovascular Surgery

Hamad Medical Corporation and Hamad General Hospital

PO Box 3050, Doha (Qatar)

Tel.+974 439 2642, Fax +974 439 2454, E-Mail aymanco65@yahoo.com 


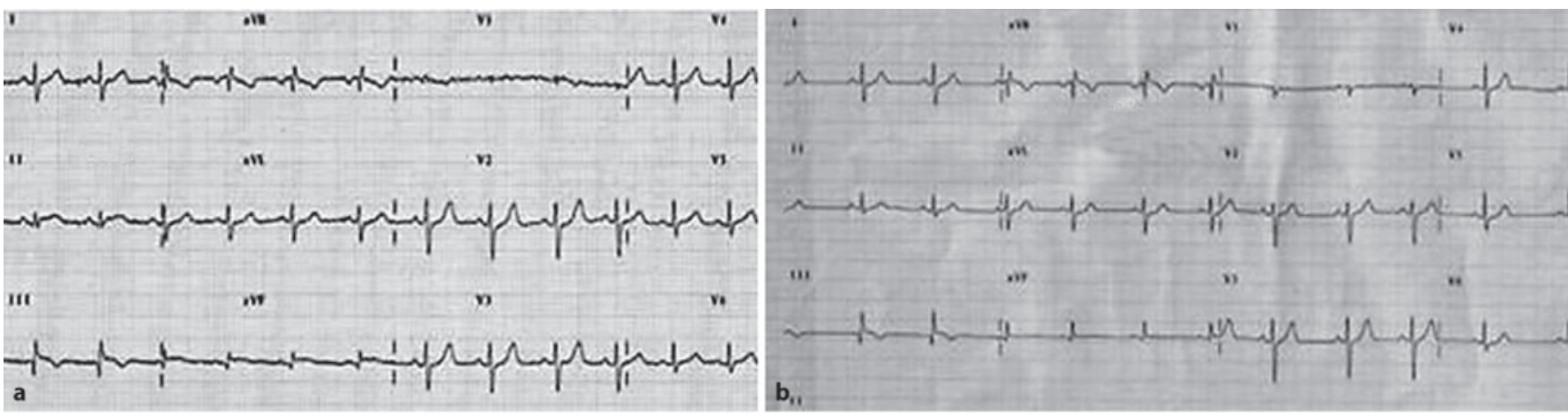

Fig. 1. ECG on arrival. a Low-voltage complexes and ST segment elevation in limb leads 2,3 and aVF. b ECG on the fourth day showing resolution of ST segment elevation.
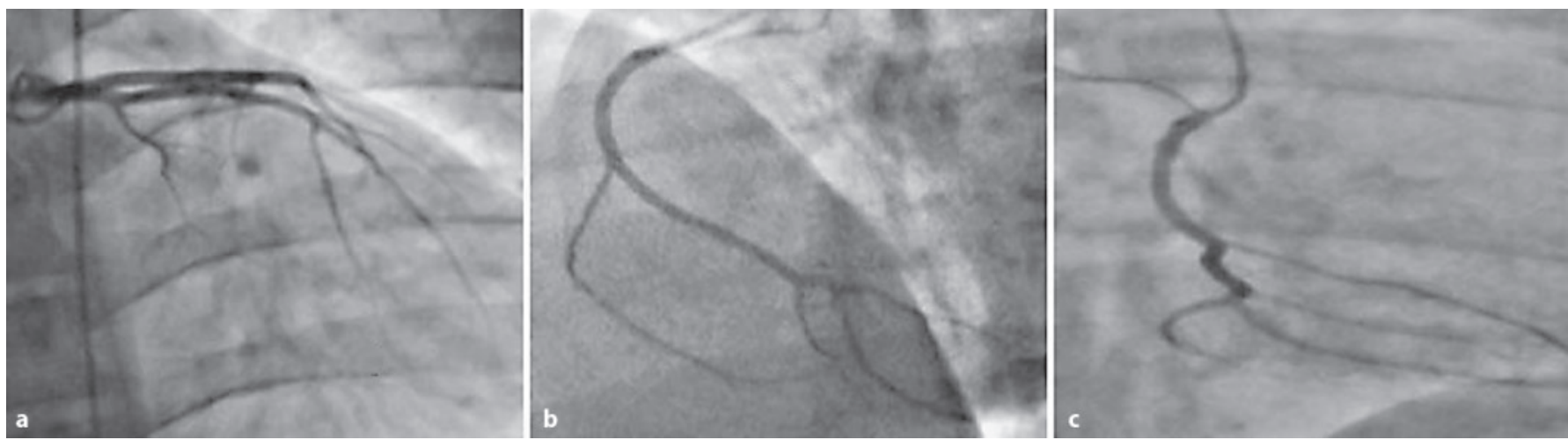

Fig. 2. The coronary angiogram reveals patent left (a) and right (b, c) coronary arterial systems.

radiating to the left shoulder and arm, increasing in severity the night prior to admission. It was not associated with sweating, shortness of breath or palpitation. Physical examination revealed: morbidly obese; weight $139.5 \mathrm{~kg}$, height $170 \mathrm{~cm}$ (BMI 48.3), afebrile and no lower limb edema. The abdomen was soft and lax, and the chest was clear. Cardiovascular examination showed: blood pressure 100/62 mm Hg, pulse 82 beats/min, jugular venous pressure was not elevated, normal S1S2 with no murmur. ECG showed low voltage, normal sinus rhythm, ST segment elevation in the inferior leads (fig. 1). Cardiac enzymes were elevated: CPK (normal 5-232 U/l), 575, 212; CPK-MB (normal <5 ng/l), 29.9, 17.3, 8.5; troponin (normal $<0.1 \mathrm{ng} / \mathrm{l}$ ), 2.6, 0.78, respectively; C-reactive protein (normal $<6 \mathrm{mg} / \mathrm{l}$ ), 12.5; ESR (normal $<15 \mathrm{~mm} / \mathrm{h}$ ), 16. Cholesterol: 4.95 (normal $<5.1 \mathrm{mmol} / \mathrm{l}$ ); triglycerides: 2.1 (borderline: $1.7-2.1 \mathrm{mmol} / \mathrm{l}$ ); HDL: $0.77 \mathrm{mmol} / \mathrm{l}$, and LDL: $3.22 \mathrm{mmol} / \mathrm{l}$. Serum levels of ethanol and cocaine were undetectable. An echocardiogram showed mildly impaired left ventricular systolic function (ejection fraction: 45\%), trivial mitral regurgitation, hypokinesia of the inferior wall and normal right ventricular systolic pressure. There was no evidence of intracar- diac shunt, mass or thrombi. He was admitted to the coronarycare unit as a case of inferior MI with late presentation; he received aspirin and heparin, tirofiban and isosorbide dinitrate infusion. A coronary angiogram was performed on the second day of admission and revealed patent epicardial coronary arteries (fig. 2). The patient was followed up by a dietitian and endocrinologist, who started short- and long-term plans for weight reduction and family counseling. The hospital stay was uneventful, and he returned home on the fourth day on a regimen of aspirin 150 $\mathrm{mg}$ once daily, isosorbide dinitrate retard $20 \mathrm{mg}$ once daily, diltiazem $60 \mathrm{mg} 3$ times per day and atorvastatin $20 \mathrm{mg}$ once daily.

\section{Discussion}

Obesity is a global problem, affecting an estimated 300 million people worldwide. Its prevalence is increasing in both developing and developed countries throughout the 
world, pertaining to people of all ages and all socioeconomic levels [7]. It has been estimated, using age- and sex-specific BMI criteria, that $10.4 \%$ of children $2-5$ years of age, $15.3 \%$ of children $6-11$ years of age and $15.5 \%$ of adolescents 12-19 years of age are overweight [8]. Compared to the international standard [1], 10-year-old male children from the United Arab Emirates had 1.7 times the rate of obesity and 1.9 times at 18 years, while female children from the United Arab Emirates have 1.8 times the rate of obesity at 10 and 18 years of age. The overall level of overweight and obesity among adolescent Kuwaitis aged $10-14$ years is $30.9 \%$ [2] and $26 \%$ among Saudi adolescents aged 10-14 years [3]. In a sample of 800 boys in the age group of 14-19 years in Qatar, 33.1\% were overweight, while the cardiovascular disease risk factor of obesity was more prominent among women $(528,78.3 \%)$ than among men $(334,68.9 \%)$ in older patients [4].

Excess weight is associated with higher mortality and cardiovascular events [9]. About $10 \%$ of all patients with AMI and nearly $20 \%$ of those under 35 years of age do not have coronary atherosclerosis demonstrated by coronary angiography, necropsy or both. Around half of nonatherosclerotic AMI patients have angiographically normal coronary arteries [10]. The possible reasons include poor angiographic technique so that a significant coronary artery stenosis is missed, small-vessel disease, hypercoagulable states, coronary embolism, coronary trauma and coronary vasospasm. Intravascular ultrasound studies documented atherosclerotic plaques that failed to encroach on the lumen of the involved coronary artery. In these patients, it was hypothesized that one of these small, intramural atherosclerotic lesions had ruptured, thereby leading to coronary arterial thrombosis that subsequently lysed, leaving the normal lumen intact $[5,10,11]$. Nevertheless, evidence has not been produced to show that obesity may be a risk for AMI in adolescents in the absence of the other risk factors, i.e. smoking, diabetes, hypertension, hyperlipidemia or drug abuse. Our case demonstrates an adolescent with angiographically normal epicardial coronary arteries and inferior AMI. This patient was not given thrombolytic therapy because of late presentation. His electrocardiographic changes normalized, and the chest pain subsided after starting antianginal medications. The patient does not have a significant risk factor apart from morbid obesity. The mechanisms whereby excess body fat affects the cardiovascular system include not only an indirect effect on the vascular system through risk factors like dyslipidemia, hypertension, obstructive sleep apnea or insulin resistance, but also an enhanced inflammatory state, a high turnover of free fat- ty acids with a lipotoxic effect on myocardial cells and the potential effects of high levels of leptin $[10,12]$. Obesity has been shown to be independently associated with coronary endothelial dysfunction in patients with normal or mildly diseased coronary arteries [11]. There was no evidence that obesity might initiate coronary artery spasm. The provocation of coronary artery spasm during the acute stage of MI carries a high risk so that in most cases the diagnosis was based on the patency of the coronaries during elective coronary angiography in addition to the clinical and electrocardiographic evidence of acute coronary events. Lack of an intravascular ultrasound study in our case is one of the limitations. In this case MI may be due to coronary spasm, invisible ruptured plaque or recanalized thrombus, and all are related to the obesity effect. However, it is an interesting case for further assessment that may re-address the role of obesity in AMI in such an age group.

\section{Conclusion}

In the absence of well-known risk factors for coronary artery disease, obesity might be the sole risk for MI at a young age. This hypothesis warrants further supportive studies that in turn will have major implications on therapy and risk stratification in obese teens. Public education and awareness of this complication at a young age are warranted. 


\section{References}

$>1$ Al-Haddad FH, Little BB, Abdul Ghafoor AG: Childhood obesity in United Arab Emirates schoolchildren: a national study. Ann Hum Biol 2005;32:72-79.

$\checkmark 2$ Al-Isa AN: Body mass index, overweight and obesity among Kuwaiti intermediate school adolescents aged 10-14 years. Eur J Clin Nutr 2004;58:1273-1277.

$\checkmark 3$ Magbool GM: Body mass index of Saudi children aged 6 to 16 years from the Eastern province. Ann Saudi Med 1994;14:495-498.

$\checkmark 4$ Bener A, Al-Suwaidi J, Al-Jaber K, Al-Marri $\mathrm{S}$, Dagash MH, Elbagi IE: The prevalence of hypertension and its associated risk factors in a newly developed country. Saudi Med J 2004;25:918-922.
5 Glover MU, Kuber MT, Warren SE, Vieweg WV: Myocardial infarction before age 36: risk factor and arteriographic analysis. Am J Cardiol 1982;49:1600-1603.

6 Lopez-Jimenez F, Jacobsen SJ, Reeder GS, Weston SA, Killian JM, Meverden R, Roger VL: Prevalence of risk factors for coronary disease in myocardial infarction in the community. J Am Coll Cardiol 2003;41:291A.

7 World Health Organization: Controlling the global obesity epidemic. 2002. http://www. who.int/nut/obs htm.

8 US Preventive Services Task Force: Screening and interventions for overweight in children and adolescents: recommendation statement. Pediatrics 2005;116:205-209.

$>9$ Lopez-Jimenez F, Malinski M, Gutt M, Sierra-Johnson J, Wady Aude Y, Rimawi AA, Mego PA, et al: Recognition, diagnosis and management of obesity after myocardial infarction. Int J Obesity 2005;9:137-141.
10 Tun A, Khan IA: Myocardial infarction with normal coronary arteries: the pathologic and clinical perspectives. Angiology 2001; 52:299-304.

1 Al Suwaidi J, Higano ST, Holmes DR Jr, Lennon R, Lerman A: Obesity is independently associated with coronary endothelial dysfunction in patients with normal or mildly diseased coronary arteries. J Am Coll Cardiol 2001;37:1523-1538.

12 Mark AL, Correia ML, Rahmouni K, Haynes WG: Selective leptin resistance: a new concept in leptin physiology with cardiovascular implications. J Hypertens 2002;20:12451250. 